\title{
Effect of lung transplantation on diaphragmatic function in patients with chronic obstructive pulmonary disease
}

Th Wanke, M Merkle, D Formanek, U Zifko, G Wieselthaler, H Zwick, W Klepetko, O C Burghuber

\begin{abstract}
Background - To date there are no data on the effects of lung transplantation on diaphragmatic function in patients with end stage chronic obstructive pulmonary disease (COPD). It is not known whether the relation between the transdiaphragmatic pressure (PDI) and lung volume is altered in recipients after transplantation as a result of changes in diaphragmatic structure caused by chronic hyperinflation. The effect of lung transplantation on diaphragmatic strength was determined in patients with COPD and the relation between postoperative PDI and lung volume analysed. Methods - Diaphragmatic strength was assessed in eight double lung transplant recipients, six single lung transplant recipients, and in 14 patients with COPD whose lung function was similar to those of the transplant recipients preoperatively. PDI obtained during unilateral and bilateral phrenic nerve stimulation at $1 \mathrm{~Hz}$ (twitch PDI) at functional residual capacity (FRC) and during maximal sniff manoeuvres (sniff PDI) at various levels of inspiratory vital capacity (VCin) served as parameters for diaphragmatic strength. Sniff PDI assessed at the various VCin levels were used to analyse the PDI/lung volume relation.
\end{abstract}

Results - Lung transplantation caused a reduction in lung volume, especially in the double lung transplant recipients. As a consequence sniff PDI was higher in the double lung transplant recipients than in the patients with COPD at all levels of VCin analysed. However, sniff PDI values analysed at comparable intrathoracic gas volumes were not reduced in the patients with COPD when compared with those who underwent lung transplantation. Bilateral twitch PDI values were similar in the patients with COPD and in the lung transplant recipients. In the single lung transplant recipients unilateral twitch PDI values were similar on the transplanted and the non-transplanted side. The relation between PDI and lung volume was similar in the patients with COPD and in the lung transplant recipients.

Conclusions - In patients with COPD lung transplantation leads to an increase the maximal sniff induced PDI values by placing the diaphragm in a more favour- able position for pressure generation. Since patients with COPD and postoperative lung transplant recipients showed similar PDI/lung volume relations, this suggests that chronic pulmonary hyperinflation does not cause major functional alterations of the diaphragm.

(Thorax 1994;49:459-464)

In recent years there has been continuous interest in diaphragmatic function in patients with chronic obstructive pulmonary disease (COPD). Histological studies have provided conflicting data as to whether the diaphragm undergoes work hypertrophy, ${ }^{12}$ atrophy, ${ }^{34}$ or neither ${ }^{5}$ in the setting of the altered ventilatory mechanics of COPD. Studies analysing respiratory muscle performance in patients with COPD in terms of strength and endurance have also yielded controversial results. Reports have ranged from impaired, ${ }^{6}$ improved, ${ }^{7}$ to unchanged $^{8}$ inspiratory muscle performance. It has recently been shown, in a study where transdiaphragmatic pressure (PDI) values induced by bilateral phrenic nerve stimulation served as parameters for diaphragmatic strength, that diaphragmatic function in patients with stable COPD is as good as in normal subjects. ${ }^{9}$ It is known, however, that PDI recorded during bilateral phrenic nerve stimulation can detect only severe diaphragmatic dysfunction. ${ }^{10}$

Animal studies have shown that chronic shortening of the diaphragm reduces its sarcomeres, resulting in a shift of its entire lengthtension curve to a shorter length. ${ }^{11}$ Whether this adaptation occurs in emphysematous human subjects remains to be seen.

Transplantation is now a treatment option in patients with end stage obstructive lung disease. ${ }^{12}$ Although single and double lung transplantation clearly improve lung function, little is known about the effects of lung transplantation on respiratory muscle function, especially the diaphragm. In one study double lung transplantation improved maximal inspiratory pressure, ${ }^{13}$ but the effects of changes in preoperative and postoperative lung volumes were not taken into account, making interpretation of pressure changes difficult. Very little is known about diaphragm forcelength characteristics in lung transplant recipients. If chronic pulmonary hyperinflation leads to a loss of diaphragmatic sarcomeres, lung transplant recipients should generate 
their maximal PDI values not at residual volume (RV) and functional residual volume (FRC), but at higher lung volumes after the transplantation.

By measuring PDI during maximal sniff manoeuvres and during supramaximal phrenic nerve stimulation at various levels of inspiratory vital capacity (VCin) we have tried to answer the following questions: (1) does single or double lung transplantation in patients with end stage obstructive lung disease improve diaphragmatic strength; and (2) do postoperative lung transplant recipients have an altered relation between PDI and lung volume when compared with that of patients with COPD not undergoing transplantation?

\section{Methods}

\section{PATIENTS}

Fourteen patients with severe COPD and 14 lung transplant recipients (eight double lung transplant (DLT) and six single lung transplant (SLT) recipients) entered the study. Five of the 14 patients with COPD received double lung transplants and two single lung transplants, and were studied before and after the operation. The underlying disease of all lung transplant recipients was obstructive lung disease. In one of the eight DLT recipients, two of the six SLT recipients, and one of the 14 patients with COPD the obstructive lung disease was secondary to emphysema due to $\alpha_{1}$-antitrypsin deficiency. The patients with COPD and the preoperative transplant recipients all had (1) airflow obstruction $\left(\mathrm{FEV}_{1}\right.$ $<50 \%$ predicted and a ratio of $\mathrm{FEV}_{1}$ to forced vital capacity less than 0.5 ); (2) substantial pulmonary hyperinflation (FRC $>130 \%$ predicted); and (3) a stable clinical state - that is, no acute respiratory exacerbation for one month before the study. Patients with coexistent diseases such as left ventricular dysfunction, renal failure, alcoholism, or neuromuscular disease were excluded. Eight of the 14 patients with COPD were oxygen dependent and 11 took oral corticosteroids with an average dose of less than $30 \mathrm{mg}$ prednisone per day. Preoperative medication also included corticosteroids in seven of the 14 lung transplant recipients at a daily dose of less than $30 \mathrm{mg}$. Postoperatively all lung transplant recipients received immunosuppressive therapy including corticosteroids, azathioprine, and cyclosporin. Azathioprine was administered at a dose of $1-2 \mathrm{mg} / \mathrm{kg} / \mathrm{day}$, and the daily dose of oral prednisone was $0 \cdot 2-0.3 \mathrm{mg} / \mathrm{kg}$. Cyclosporin was administered orally to achieve plasma levels of $300-400 \mathrm{ng} / \mathrm{l}$.

Four of the DLT recipients and two of the SLT recipients were studied 21-28 days after transplantation, the remaining lung transplant recipients 1-3 months after transplantation. All patients gave consent after the nature of the tests had been explained to them, and the study was approved by the ethics review committee of the hospital.

\section{MATERIALS AND MEASUREMENTS}

Lung function tests included spirometry and whole body plethysmography. Spirometry was performed by using an open system with integration of the flow signal; whole body plethysmography was carried out by the constant volume method (Jaeger, Würzburg, Germany). The predicted normal values were those of Quanjer. ${ }^{14}$

Oesophageal and gastric pressures were measured by a water perfused catheter system, ${ }^{15}$ and PDI was calculated by subtracting oesophageal pressure (POES) from gastric pressure (PGA). To measure PDI during unilateral and bilateral phrenic nerve stimulation at $1 \mathrm{~Hz}$ (twitch PDI) both right and left phrenic nerves were stimulated percutaneously at the posterior border of the sternomastoid muscle at the level of the upper margin of the thyroid cartilage using a hand held, felt tipped bipolar stimulating electrode (Medelec, Surrey, UK). Suprathreshold square wave impulses of $0.2 \mathrm{~ms}$ duration were applied. The compound action potential of the diaphragm was recorded by surface electrodes placed $3-5 \mathrm{~cm}$ apart in the seventh or eighth intercostal space with the anterior electrodes in the anterior axillary line. These electrodes were connected to an electromyograph (Medelec, Surrey, UK). The compound action potentials evoked from each stimulated hemidiaphragm were monitored on a storage oscilloscope.

Two pairs of linearised magnetometers (Segadat, Vienna, Austria) were used to monitor changes in the rib cage configuration and in the abdominal anteroposterior diameter. One pair was applied at the level of the lower end of the sternum and the other pair at the level of the umbilicus. This output was displayed on an oscilloscope in front of the patient so that the shapes of the rib cage and the abdomen could be kept constant at the beginning of the twitch stimulations and the sniff manoeuvres at the various lung volumes analysed.

Diaphragmatic length, expressed as the total diaphragmatic length index, was measured on posteroanterior and right lateral chest films taken seated at FRC, as described by Braun and coworkers. ${ }^{16}$

\section{STUDY DESIGN}

Initially the patients performed maximal sniff manoeuvres at various intrathoracic gas volumes. They were asked to perform short sharp sniffs as hard as possible through the nose with the mouth closed, and without a noseclip. No attempt was made to control the relative contribution of PGA or POES to PDI. Sniffs were initially carried out at resting end expiration (FRC). Ten sniffs were performed at FRC and the five highest pressure values were selected for analysis. An interval of 30-45 seconds was allowed between each sniff. A further series of 10 sniff manoeuvres was then performed after maximal expiration (RV). To ensure a constant maximal expiration breathing was registered on a bell spirometer connected to a well fitting face mask, through which the patient had to breathe as he watched 
the curve on the spirometer. The mask had a preformed hole for a catheter used for measuring PDI. The five highest PDI values were selected. Finally, the patient was required to inhale maximally and then exhale to a predetermined lung volume (expressed as a percentage of VCin) clearly marked on the spirometer. The first volume was $60 \%$, the second $80 \%$, and the third $90 \%$ of the VCin. At each level the best five of 10 sniffs were selected for analysis.

During phrenic nerve stimulation changes in lung volume were also registered on the bell spirometer. The face mask was replaced by a mouthpiece, through which the patient breathed, which was connected to the bell spirometer. The twitch responses to unilateral and bilateral phrenic nerve stimulation were recorded at FRC. Bilateral stimulation of the phrenic nerves was performed eight times, and the five highest twitch induced PDI values were analysed. In the six SLT recipients the PDI response to right and left unilateral phrenic stimulation was also recorded. Each time eight twitches were recorded on the left and then on the right side the five highest twitch induced PDI values were used for analysis. All stimulations were performed with the diaphragm relaxed, after breathing out and relaxing at end expiration, and then the mouthpiece was closed by a shutter. Absence of spontaneous electrical activity was taken as the criterion for diaphragmatic relaxation.

All patients who were oxygen dependent received oxygen throughout each test.

\section{STATISTICAL ANALYSIS}

In determining differences between the patients with COPD and lung transplant recipients, the non-parametric Kolmogorov-Smirnov test was used. Linear regression analysis using the least squares method was performed in each subject with original data to investigate the relation between PDI and lung volume. $p$ values of $<0.05$ were accepted as statistically significant. All data are presented as mean (SD) unless otherwise indicated.

\section{Results}

There were no significant differences in the anthropometric data between the patients with COPD and the lung transplant recipients. The general characteristics of the subjects are summarised in table 1. The COPD patient group consisted of eight men and six women, the DLT recipient group of five men and three women, and the SLT recipient group of three men and three women. The mean pulmonary function parameters and blood gas tensions of the patient groups are given in table 2 . The lung function data obtained from the patients with COPD and the lung transplant recipients preoperatively were similar. All transplant recipients, especially the DLT recipients, showed a significant improvement in their lung function and arterial blood gases postoperatively. Diaphragmatic length remained significantly reduced in the patients with
Table 1 Mean (SD) physical characteristics of the patients with chronic obstructive pulmonary disease (COPD) and the lung transplant recipients

\begin{tabular}{lccl}
\hline & $\begin{array}{l}\text { COPD } \\
\text { patients } \\
(n=14)\end{array}$ & $\begin{array}{l}\text { Lung transplant } \\
\text { recipients } \\
(n=14)\end{array}$ & $p$ \\
\hline Age (years) & $51 \cdot 9(7 \cdot 5)$ & $48 \cdot 6(8 \cdot 8)$ & NS \\
Height $(\mathrm{cm})$ & $172 \cdot 7(10 \cdot 0)$ & $169.9(9 \cdot 7)$ & NS \\
Weight $(\mathrm{kg})$ & $69.4(9 \cdot 1)$ & $68.3(11 \cdot 1)$ & NS
\end{tabular}

NS = not significant

COPD compared with that in the DLT recipients after surgery. The mean total diaphragmatic length index was $0.20(0.02)$ and 0.28 $(0.02)$ in the patients with COPD and the DLT recipients, respectively $(p<0.001)$.

PHRENIC NERVE STIMULATION AT FRC

The mean value of the bilateral twitch PDI in the patients with COPD was $2.05(0.57) \mathrm{kPa}$, in the postoperative SLT recipients it was $2.47(0.85) \mathrm{kPa}$, and in the postoperative DLT recipients $2.58(0.64) \mathrm{kPa}$. Although the twitch PDI value was greater in the lung transplant recipients than in the patients with COPD, this difference was not statistically significant despite the fact that the intrathoracic gas volume at FRC was higher in the patients with COPD than in the lung transplant recipients. The contribution of twitch induced PGA to the bilateral twitch PDI was, on average, $35(10) \%$ in the patients with COPD and $33(11) \%$ in the lung transplant recipients. The measurements were reproducible, with a mean coefficient of variation (CV) for values within the same subject of less than $11 \%$. Although four of the six SLT recipients had the right lung transplanted, stimulation of the left phrenic nerve resulted in larger twitch PDI (mean $1 \cdot 10(0 \cdot 26) \mathrm{kPa})$ than when the right nerve was stimulated (mean $0.88(0.28) \mathrm{kPa})$, but this difference was not statistically significant. The $\mathrm{CV}$ for unilateral twitch PDI values was less than $13 \%$ in each SLT recipient.

\section{MAXIMAL SNIFF INDUCED Pd VALUES ASSESSED} AT VARIOUS LEVELS OF VCin

The sniff manoeuvres were performed by all subjects without difficulty. The contribution of PoEs and PGA to sniff PDI varied, though none had a negative PGA at any lung volume. In all subjects the individual CV of sniff PDI at FRC ranged from $6 \%$ to $8 \%$. With increasing lung volume the $\mathrm{CV}$ became greater due to the reduction of the mean sniff PDI values and the fairly constant standard deviation. However, for each participant the $\mathrm{CV}$ did not exceed $15 \%$ at each lung volume. When differences in intrathoracic gas volumes were not taken into account DLT recipients had significantly higher and SLT recipients slightly higher sniff PDI values postoperatively at RV, FRC, $60 \%$, $80 \%$, and $90 \%$ of VCin levels when compared with the patients with COPD (table 3 ). In all three patient groups the highest pressure values were achieved at RV and FRC. There was no evidence that SLT and DLT recipients generated higher PDI values postoperatively at higher lung volumes than at RV or FRC. In 
Table 2 Mean (SD) lung function parameters and blood gas values in the patients with chronic obstructive pulmonary disease (COPD) and in the lung transplant recipients preoperatively and postoperatively

\begin{tabular}{|c|c|c|c|c|}
\hline & $\begin{array}{l}\text { COPD } \\
\text { patients } \\
(n=14)\end{array}$ & $\begin{array}{l}\text { Lung transplant } \\
\text { recipients } \\
\text { preoperative } \\
(n=14)\end{array}$ & $\begin{array}{l}\text { Single lung } \\
\text { transplant } \\
\text { recipients } \\
(n=6)\end{array}$ & $\begin{array}{l}\text { Double lung } \\
\text { transplant } \\
\text { recipients } \\
(n=8)\end{array}$ \\
\hline $\begin{array}{l}\text { VCin }(\%) \\
\text { FEV } \\
1 \%) \\
\text { TLC }(\%) \\
\text { FRC }(\%) \\
\text { RV }(\%) \\
\text { Raw }(\mathrm{kPa} / \mathrm{l} / \mathrm{s}) \\
\mathrm{PaO}_{2}(\mathrm{kPa}) \\
\mathrm{PaCO}_{2}(\mathrm{kPa})\end{array}$ & $\begin{array}{c}58 \cdot 3(12.5) \\
30 \cdot 1(9 \cdot 7) \\
133.3(17.6) \\
218 \cdot 5(22 \cdot 1) \\
309 \cdot 3(38.4) \\
0.75(0.25) \\
7.9(1 \cdot 1) \\
5 \cdot 8(0.9)\end{array}$ & $\begin{array}{c}55.8(11.7) \\
27.5(8.8) \\
125.9(15.3) \\
212.9(18.3) \\
290.0(33.7) \\
0.78(0.21) \\
8.4(1.2) \\
5.8(1.1)\end{array}$ & $\begin{array}{c}66.9(8.0) \\
54 \cdot 2(13.6) \\
106 \cdot 3(3 \cdot 7) \\
132.9(9 \cdot 6) \\
202 \cdot 5(21.9) \\
0.23(0.04) \\
11.6(1.0) \\
4.6(0.8)\end{array}$ & $\begin{array}{c}72 \cdot 2(11 \cdot 5) \\
64 \cdot 1(15.0) \\
89 \cdot 6(16.7) \\
120 \cdot 4(8 \cdot 8) \\
143 \cdot 3(17 \cdot 2) \\
0 \cdot 13(0.06) \\
11 \cdot 8(1 \cdot 2) \\
4 \cdot 8(0 \cdot 7)\end{array}$ \\
\hline
\end{tabular}

VCin = inspiratory vital capacity; $\mathrm{FEV}_{1}=$ forced expiratory volume in one second; TLC = total lung capacity; $F R C=$ functional residual capacity; $R V=$ residual volume; $R a w=$ airway resist ance; $\mathrm{PaO}_{2}$ and $\mathrm{PaCO}_{2}=$ arterial partial pressure of oxygen and carbon dioxide. VCin, FEV, TLC FRC, and RV are given as \% predicted values (sources of predicted values are given in the text).

addition, the PDI values, when related to the sniff PDI assessed at RV, decreased in all three groups by a similar percentage (table 4 ).

\section{RELATION BETWEEN SNIFF PDI AND LUNG} VOLUME (AS \% PREDICTED TLC)

In all subjects there was a significant decrease in sniff PDI with increasing lung volume (expressed as \% predicted TLC; figure). The decrease in the sniff PDI was always linear. The mean slopes and intercepts of the plots for all patient groups were used to construct regression equations for the relation between sniff PDI and lung volume. The regression equations were: sniff PDI $=-0 \cdot 141 \times \%$ predicted TLC + 21.22 $(r=0.95, \quad \mathrm{p}<0.001)$ for the patients with COPD, sniff PDI $=-0.178 \times \%$ predicted TLC $+21.30 \quad(r=0.94, p<0.001)$ for the SLT recipients, and sniff PDI $=-0.218 \times \%$ predicted TLC +21.87 $(r=0.95, \mathrm{p}<0.001)$ for the DLT recipients. There was no evidence that postoperative SLT and DLT recipients generated higher sniff PDI values than the patients with COPD at comparable intrathoracic gas volumes. There was also no evidence that the sniff PDI values increased initially in the postoperative SLT and DLT recipients with increasing lung volumes and then decreased only with further increased lung volumes (as would be the case when chronic pulmonary hyperinflation leads to diaphragmatic structural alterations by

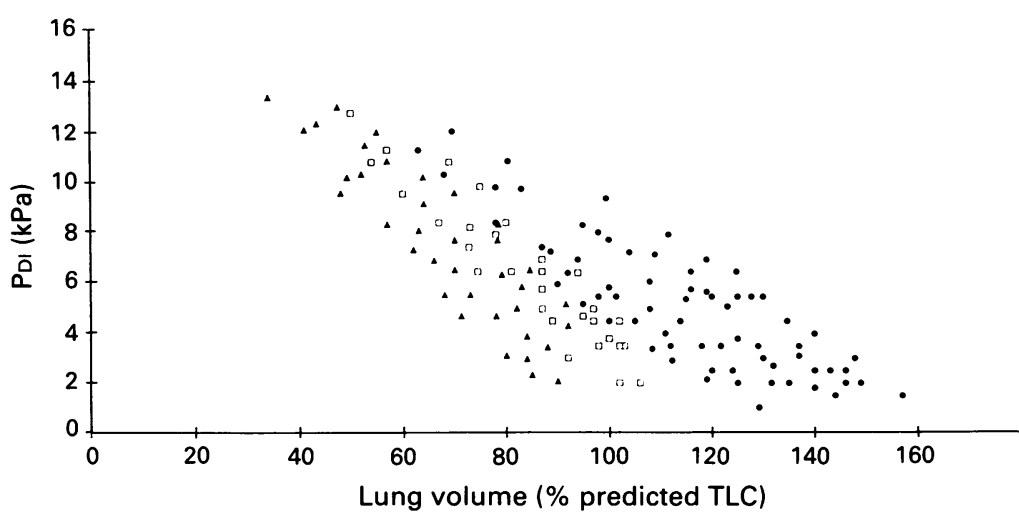

Maximal sniff induced transdiaphragmatic pressure (PDI) plotted against lung volume expressed as a percentage of the predicted total lung capacity (TLC). Each symbol represents the mean value of the five highest of 10 PDI values at the various lung volumes analysed. 0 , patients with $C O P D ; \square, S L T$ recipients; $\triangle, D L T$ recipients.
Table 3 Mean (SD) maximal sniff induced transdiaphragmatic pressure (PDI) in the patients with chronic obstructive pulmonary disease (COPD), single lung transplant ( $S L T$ ) and double lung transplant (DLT) recipients at the various lung volumes analysed

\begin{tabular}{llcl}
\hline & $\begin{array}{l}\text { COPD } \\
\text { patients } \\
(k P a) \\
(n=14)\end{array}$ & $\begin{array}{l}\text { SLT } \\
\text { recipients } \\
(k P a) \\
(n=6)\end{array}$ & $\begin{array}{l}\text { DLT } \\
\text { recipients } \\
(k P a) \\
(n=8)\end{array}$ \\
\hline RV & $8.64(2.20)$ & $10.0(1.80)$ & $12.75(1.85)^{*}$ \\
FRC & $6.36(1.54)$ & $7.48(1.47)$ & $9.50(1.62)^{*}$ \\
$60 \%$ VCin & $4.50(1.48)$ & $5.53(1.41)$ & $6.93(1.73)^{*}$ \\
$80 \%$ VCin & $3.21(1.21)$ & $3.97(1.25)$ & $4.98(1.36)^{\dagger}$ \\
$90 \%$ VCin & $2.14(0.99)$ & $2.83(0.69)$ & $3.86(1.48)^{\dagger}$ \\
\hline
\end{tabular}

$\mathbf{R V}=$ residual volume; $\mathrm{FRC}=$ functional residual capacity; VCin = inspiratory vital capacity

${ }^{*} \mathrm{p}<0.001 v$ patients with COPD; $\dagger \mathrm{p}<0.01 v$ patients with COPD. PDI values in the patients with COPD and the SLT recipients were not significantly different.

Table 4 Mean (SD) maximal sniff induced transdiaphragmatic pressure (PDI) in the patients with chronic obstructive pulmonary disease (COPD), single lung transplant (SLT) and double lung transplant (DLT) recipients, as a percentage of PDI obtained at residual volume

\begin{tabular}{llll}
\hline & $\begin{array}{l}\text { COPD } \\
\text { patients }\end{array}$ & $\begin{array}{l}\text { SLT } \\
\text { recipients }\end{array}$ & $\begin{array}{l}\text { DLT } \\
\text { recipients }\end{array}$ \\
\hline FRC & $74 \cdot 2(9 \cdot 4)$ & $74 \cdot 1(12 \cdot 9)$ & $75 \cdot 9(14 \cdot 8)$ \\
$60 \%$ VCin & $53 \cdot 4(13 \cdot 6)$ & $55 \cdot 5(5 \cdot 2)$ & $51 \cdot 7(9 \cdot 1)$ \\
$80 \%$ VCin & $37 \cdot 4(10 \cdot 4)$ & $41 \cdot 2(9 \cdot 5)$ & $36 \cdot 0(15 \cdot 1)$ \\
$90 \%$ VCin & $26.0(14 \cdot 4)$ & $27 \cdot 4(6 \cdot 6)$ & $28 \cdot 2(12 \cdot 1)$ \\
\hline
\end{tabular}

$\overline{\mathrm{FRC}}=$ functional residual capacity; VCin $=$ inspiratory vital capacity.

absorbing sarcomeres). On the contrary, when the differences in respiratory system recoil between the patients with COPD and the lung transplant recipients were not taken into account the sniff PDI values of the former were even higher than those of the SLT and DLT recipients. The mean slopes of the regression lines for the relation between PDI and lung volume were also steeper in the transplant recipients than in the patients with COPD. When we consider the data of Decramer et al concerning the differences of respiratory system recoil between normal subjects and patients with COPD (the difference amounts to about $2.5 \mathrm{kPa}$ between $70 \%$ and $100 \%$ predicted TLC, and about $4 \mathrm{kPa}$ between $100 \%$ and $130 \%$ predicted TLC), ${ }^{17}$ it becomes evident that patients with COPD and transplant recipients generated very similar sniff $\mathrm{PDI}$ values at comparable intrathoracic gas volumes, and that the PDI/lung volume relations were also very similar in the three patient groups.

\section{Discussion}

Our study has shown that in patients with advanced COPD lung transplantation causes an increase in the maximal sniff induced PDI values. This beneficial effect on diaphragmatic strength is because lung transplantation places the diaphragm in a more favourable position for pressure generation. The study also shows that both patients with COPD and postoperative lung transplant recipients have very similar PDI/lung volume relations.

The abnormalities of pulmonary function in patients with COPD adversely affect the res- 
piratory muscles, especially the diaphragm. In COPD the diaphragm becomes shorter and flatter because of lung hyperinflation, causing it to contract from shorter than normal initial fibre length and placing it on an unfavourable part of its force-length curve. Flattening further increases the radius of its curvature and, according to Laplace's law, whatever tension is developed in the contracting diaphragm is poorly converted to transdiaphragmatic pressure in this state. In addition, respiratory muscles in patients with COPD may be in a state of chronic fatigue. ${ }^{18} 19$ Lung transplantation may improve diaphragmatic strength by reducing lung volume ("deflation"), by reversing respiratory muscle fatigue, or both.

When the differences in intrathoracic gas volume between patients with COPD and transplant recipients were not considered the maximal sniff induced PDI values assessed at RV, FRC, $60 \%, 80 \%$, and $90 \%$ VCin were significantly higher in the DLT patients than in those with COPD. The SLT recipients could also generate higher PDI values than the patients with COPD, but this difference was not statistically significant. The sniff induced PDI values assessed in the DLT recipients at FRC were well within the normal range. ${ }^{20}$

When sniff PDI values were analysed at comparable intrathoracic gas volumes there was no evidence that transplant recipients produced higher PDI values than patients with COPD. On the contrary, as shown in the figure, the diaphragmatic function in the patients with COPD was even better than in the postoperative transplant recipients at comparable intrathoracic gas volumes, when differences in respiratory system elastic recoil between the patients with COPD and transplant recipients were not taken into account. In patients with COPD the elastic recoil of the respiratory system is pathologically reduced due to a decrease in lung elastic recoil. ${ }^{17}$ Lung transplantation normalises the respiratory system characteristics. The sniff technique is not an isometric one but involves shortening of the diaphragm, with a mean volume change of $500 \mathrm{ml}$ if the sniff is maximal. ${ }^{21}$ One must therefore consider the effects of respiratory system recoil when comparing maximal sniff induced PDI values in patients with advanced COPD with those in lung transplant recipients. When considering the data of Decramer et al on differences of respiratory system recoil between normal subjects and patients with $\mathrm{COPD}^{17}$ there is no evidence that diaphragmatic strength in our patients with COPD was reduced compared with that in transplant recipients at comparable intrathoracic gas volumes. Thus, lung transplantation increases the maximal sniff induced PDI values in patients with COPD by placing the diaphragm in a more favourable position and not by reversing fatigue. Our results indicate that diaphragmatic strength is well preserved in COPD, and are in agreement with previous studies. Animal experiments have shown that emphysema provides a considerable training stimulus for the diaphragm and inspiratory loading improves the neuromechanical ef- ficiency. ${ }^{22} 23$ In man, COPD has not been shown to reduce inspiratory muscle strength. ${ }^{7}$

In contrast to sniff PDI, the twitch PDI values in the patients with COPD at FRC were similar to those in the transplant recipients, including the DLT recipients. One could argue that phrenic nerve fibres were incompletely stimulated because during twitch stimulation the neuronal firing rate was low $(1 \mathrm{~Hz})$ as it was applied externally to the phrenic nerves. During maximal sniff manoeuvres, however, the neuronal firing rate is likely to be high and may resemble a brief tetanic stimulation. The ratio of bilateral twitch PDI values to sniff induced PDI values (assessed at FRC) was between 0.24 and 0.36 in the patients with COPD and in the transplant recipients. Similar values were reported for the twitch/tetanus ratio in isolated diaphragm muscle strips and mammalian limb muscles studied in vitro ${ }^{2425}$ showing that, during transcutaneous phrenic nerve stimulation, most, if not all, phrenic nerve fibres are stimulated. Also patients with COPD with shortened diaphragmatic muscle fibre lengths due to hyperinflation could fully activate their diaphragms during a maximal voluntary contraction. This finding agrees with a previous study in humans which showed that maximal voluntary activation of the motor neurone pools is possible even at shorter than optimal skeletal muscle length. ${ }^{26}$

All lung transplant recipients had immunosuppressive therapy with corticosteroids, azathioprine, and cyclosporin, and these drugs can affect skeletal muscle function. ${ }^{2728}$ The sniff induced PDI values of the DLT recipients obtained at FRC were well within the normal range. ${ }^{20}$ Eleven of our 14 patients with end stage COPD were also taking corticosteroids and there was no evidence that they generated lower sniff induced PDI values than the transplant recipients. It is therefore unlikely that the immunosuppressive therapy influenced our results.

It has been postulated that chronic pulmonary hyperinflation may cause structural alterations of the diaphragm. ${ }^{29}$ The diaphragm may adapt to chronic shortening by reducing sarcomeres so that the whole length-tension curve is shifted to a shorter length. An animal study has shown that striated muscles can adjust their sarcomere number to generate maximal tension at a longer or shorter length than optimal when chronically overstretched or shortened, ${ }^{30}$ but after being allowed to return to a normal length the length-tension curves and sarcomere number became normal after four weeks. Whether the diaphragmatic forcelength characteristics are affected by chronic shortening or overstretching is controversial. Animal studies have shown that elastase induced emphysema leads to a reduction in the number of diaphragmatic sarcomeres. ${ }^{1131}$ However, another study has shown that the effective operating length range of the diaphragm is greater than that in other skeletal muscles. ${ }^{32}$ The authors of that study concluded that an exceptionally broad range of effective muscle length is of physiological advantage as it allows greater mechanical respiratory re- 
serve because the extent of shortening which the diaphragm can undergo while still effectively exerting tension is a major factor in determining maximal lung inflation. Arora and Rochester measured diaphragmatic muscle mass, thickness, and lengths in patients with COPD at necropsy and found no evidence of permanent diaphragmatic shortening. ${ }^{5}$ They did not exclude the possibility, however, that patients with COPD whose FRC is $2-3$ times normal could have structural alterations in their diaphragms. In our study nearly all the transplant recipients had FRC values twice as great as predicted before surgery, but there was no evidence that SLT or DLT recipients generated their highest sniff induced PDI values postoperatively at lung volumes higher than RV and FRC. When related to RV the PDI values in the three patient groups fell by a similar percentage at FRC, $60 \%, 80 \%$, and $90 \%$ VCin. When the effects of respiratory system elastic recoil were considered the relation of PDI to lung volume (expressed as \% predicted TLC) was similar in the patients with COPD and in the transplant recipients. One could argue that the diaphragmatic forcelength curves of the SLT and DLT recipients possibly returned to normal very quickly postoperatively so that it was not possible to show a length adaptation from chronic hyperinflation. An animal study, however, showed that two weeks of shortening were not enough to alter the length-tension characteristics of skeletal muscles ${ }^{33}$; even in the transplant recipients who were examined $21-28$ days after transplantation higher PDI values could not be generated at higher lung volumes than those at RV and FRC. These results indirectly infer that chronic pulmonary hyperinflation does not cause major structural alterations of the diaphragm.

One of the major aims in the treatment of patients with COPD is to improve some lung function parameters and their performance ability. Lung transplantation can bring some pulmonary function parameters back to normal and improve exercise capacity in combination with training programmes. ${ }^{1234}$ Our study shows that lung transplantation also has beneficial effects on the diaphragm as a pressure generator in patients with advanced COPD. It allows an increase in the maximal sniff induced PDI values as the diaphragm is in a more favourable position to generate pressure. As the relation between PDI and lung volume was similar in the patients with COPD and the transplant recipients postoperatively, chronic shortening of the diaphragm does not appear to cause major structural alterations of the diaphragm.

1 Ishikawa S, Hayes JA. Functional morphology of the diaphragm in patients with chronic obstructive lung disease. Am Rev Respir Dis 1973;108:135-8.

2 Scott JWM, Hoy J. The cross sectional area of diaphragmatic muscle fibers in emphysema measured by an auto-
mated image analysis system. $\mathcal{F}$ Pathol 1976;120:121-8.
3 Steele RH, Heard BE. Size of the diaphragm in chronic bronchitis. Thorax 1973;28:55-60.

4 Thurlbeck WM. Diaphragm and body weight in emphysema. Thorax 1978:33:483-7.

5 Arora NS, Rochester DF. COPD and human diaphragm muscle dimensions. Chest 1987;91:19-24.

6 Morrison NJ, Richardson J, Dunn L, Pardy RL. Respiratory muscle performance in normal elderly subjects and patients with COPD. Chest 1989;95:90-4.

7 Byrd RB, Hyatt RE. Maximal respiratory pressures in chronic obstructive lung disease. Am Rev Respir Dis 1968;98:848-56.

8 Newell SZ, McKenzie DK, Gandevia SC. Inspiratory and skeletal muscle strength and endurance and diaphragmatic activation in patients with chronic airway limimatic activation in patients with

9 Similowski T, Yan S, Gauthier AP, Macklem PT, Bellemare F. Contractile properties of the human diaphragm mare $\mathrm{F}$. Contractile properties of the human diaphragm during chronic

10 Mier A, Brophy C, Moxham J, Green M. Twitch pressures in the assessment of diaphragm weakness. Thorax 1989;44:990-6.

11 Farkas GA, Roussos C. Diaphragm in emphysematous hamsters: sarcomere adaptability. $\mathcal{F}$ Appl Physiol: Respir Environ Exercise Physiol 1983;54:1635-40.

12 Williams TJ, Grossman RF, Maurer JR. Long-term functional follow-up of lung transplant recipients. Clin Chest Med 1990;11:347-58.

13 Williams TJ, Patterson GA, McClean PA, Zamel N, Maurer JR. Maximal exercise testing in single and double lung transplant recipients. Am Rev Respir Dis 1992;145:101-5.

14 Quanjer PhH (ed). Standardized lung function testing. Bull Eur Physiopathol Respir 1983;19:1-95.

15 Wanke T, Schenz G, Zwick H, Ritschka L, Flicker M. Dependence of maximal sniff generated mouth and transdiaphragmatic pressures on lung volume. Thorax 1990;45:352-5.

16 Braun NMT, Arora NS, Rochester DF. Force-length relationship of the normal human diaphragm. $\mathcal{F}$ Appl Physiol 1982;53:405-12.

17 Decramer M, Demedts M, Rochette F, Billiet L. Maximal transrespiratory pressures in obstructive lung disease. transrespiratory pressures in obstructive lung
Bull Eur Physiopathol Respir 1980;16:479-90.

18 Moxham J, Morris AJR, Spiro SG, Edwards RHT, Green $M$. Contractile properties and fatigue of the diaphragm in man. Thorax 1981;36:164-8.

19 Flenley DC. Short review: inspiratory muscle training. Eur f Respir Dis 1985;67:153-8.

20 Miller JM, Moxham J, Green M. The maximal sniff in the assessment of diaphragm function in man. Clin Sci 1985;69:91-6.

21 Pertuze J, Lim TK, Watson A, Pride NB. Transdiaphragmatic pressures during static and dynamic maximum matic pressures during static and dynamic maximum inspiratory efforts in normal subjects.
pathol Respir 1987;23(Suppl 12):355s.

22 Farkas GA, Roussos C. Adaptability of the hamster diaphragm to exercise and/or emphysema. $f$ Appl Physiol: Respir Environ Exercise Physiol 1982;53:1263-72.

23 Akabas SR, Bazzy AR, Dimauro S, Haddad GG. Metabolic and functional adaptation of the diaphragm to training with resistive loads. F Appl Physiol 1989;66:529-35.

24 Bellemare F, Bigland-Ritchie B. Assessment of human diaphragm strength and activation using phrenic nerve stimulation. Respir Physiol 1984;58:263-77.

25 Close RI. Dynamic properties of mammalian skeletal muscles. Physiol Rev 1972;52:129-97.

26 Gandevia SC, McKenzie DK. Activation of human muscles at short muscle lengths during maximal static efforts. $\mathcal{f}$ at short muscle lengths duriol
Physiol 1988;407:599-613.

27 Dekhuijzen PNR, Decramer M. Steroid-induced myopathy and its significance to respiratory disease: a known disease rediscovered. Eur Respir f 1992;5:997-1003.

28 Arellano F, Krupp P. Muscular disorders associated with cyclosporin. Lancet 1991;337:915.

29 Rochester DF, Arora NS. Respiratory muscle failure. Med Clin North Am 1983;67:573-97.

30 Tabary JC, Tabary C, Tardieu C, Tardieu G, Goldspink G. Physiological and structural changes in the cat's soleus muscle due to immobilization at different lengths by muscle due to immobilization at differ

31 Kelson SG, Wolanski T, Supinski GS, Roessmann U. The effect of elastase-induced emphysema on diaphragmatic muscle structure in hamsters. Am Rev Respir Dis muscle structure

32 Kim MJ, Druz WS, Danon J, Machnach W, Sharp JT. Mechanics of the canine diaphragm. If Appl Physiol 1976;41:369-82.

33 Schottelius BA, Thomson JD, Hines HM. Capacity of skeletal muscle to develop isometric tension after prolonged shortening. Am $\mathcal{F}$ Physiol 1954;179:491-4

34 Stiebellehner L, Quittan M, End A, Grimm M, Klepetko W, Haber $\mathrm{P}$, et al. Effect of aerobic endurance training on reduced exercise capacity in patients after lung transplantation. Am Rev Respir Dis 1993;147:A333. 